\title{
Anti-CD38/CD3 Bispecific Monoclonal Antibody GBR 1342
}

National Cancer Institute

\section{Source}

National Cancer Institute. Anti-CD38/CD3 Bispecific Monoclonal Antibody GBR 1342. NCI

Thesaurus. Code C147563.

A humanized, bispecific monoclonal antibody (BsAb) against human CD3, a T-cell surface antigen, and the human cell surface glycoprotein CD38, a tumor-associated antigen (TAA), with potential antineoplastic activity. Upon administration, anti-CD38/anti-CD3 bispecific monoclonal antibody GBR 1342 binds to both CD3 on T-cells and CD38 expressed on certain tumor cells. This results in the cross-linking of T-cells and tumor cells, and induces a potent cytotoxic T-lymphocyte $(C T L)$ response ag ainst CD38expressing tumor cells. CD38, a type II transmembrane glycoprotein, is present on various immune cells and hematologic malignancies; its expression has been correlated with poor prognosis. GBR 1342 uses the proprietary bispecific engagement by antibodies based on the T-cell receptor (BEAT) platform. 